\title{
An ex vivo human aqueous humor-concentration comparison of two commercial bromfenac formulations
}

This article was published in the following Dove Press journal:

Clinical Ophthalmology

\author{
Thomas R Walters' \\ Robert J Smyth-Medina ${ }^{2}$ \\ Paul C Cockrum ${ }^{3}$ \\ 'Keystone Research, Austin, TX, \\ ${ }^{2}$ University of California, Los Angeles, \\ $\mathrm{CA},{ }^{3} \mathrm{Health}$ Kinetics, Fort Worth, \\ TX, USA
}

Purpose: The purpose of this study was to quantify the concentration of bromfenac in the aqueous humor utilizing high-performance liquid chromatography mass spectrometry between two commercial nonsteroidal anti-inflammatory drugs, using aqueous humor concentrations to characterize pharmacokinetic proportional differences between $0.075 \%$ bromfenac ophthalmic solution in DuraSite $\left(\right.$ BromSite $^{\mathbb{R}}$ ) and $0.09 \%$ bromfenac ophthalmic solution (Bromday ${ }^{\mathbb{R}}$ ).

Methods: In this multicenter, randomized, double-masked, two-arm, parallel-group, comparative, Phase II clinical trial, subjects were assigned to receive bromfenac in DuraSite or bromfenac ophthalmic solution in a 1:1 ratio. One drop of the masked test article was instilled into the study eye once a day for 2 days prior to and 3 hours prior (last instillation) to the subject's cataract surgery. Aqueous humor samples were collected upon initial cataract incision for analysis of bromfenac levels. The primary end point was aqueous humor concentration of bromfenac at Day 3, at the initiation of cataract surgery. Aqueous humor samples were collected and analyzed for bromfenac levels.

Results: A total of 60 subjects completed the study, 30 in each group. The mean bromfenac aqueous humor concentration in subjects who received bromfenac in DuraSite was more than twice $(49.33 \pm 41.87 \mathrm{ng} / \mathrm{mL}, P=0.004)$ that of subjects who received bromfenac ophthalmic solution $(23.65 \pm 16.31 \mathrm{ng} / \mathrm{mL})$ after three doses.

Conclusion: Mean bromfenac aqueous humor concentration in subjects receiving the DuraSitecontaining bromfenac in DuraSite $(0.075 \%)$ was significantly higher compared to subjects receiving bromfenac ophthalmic solution (0.09\%) after 3 days of dosing.

Keywords: pharmacokinetics, PK, ocular, NSAID, aqueous humor

\section{Introduction}

Topical nonsteroidal anti-inflammatory drugs (NSAIDs) have been used by cataract surgeons for routine cases to reduce clinically significant cystoid macular edema (CME) and improve early visual acuity. There are many NSAID formulations available in the USA. Nepafenac, ketorolac, diclofenac, flurbiprofen, and bromfenac are currently approved by the US Food and Drug Administration (FDA). With different pharmacodynamic characteristics, these NSAIDs inhibit isoforms 1 and 2 of cyclooxygenase. The pharmacology is known to prevent the biosynthesis of inflammatory mediators responsible for inflammation, producing vasodilation, altering intraocular pressure, and prompting miosis. ${ }^{1-4}$

Topical steroids have been the mainstay of therapy to control ocular inflammation. ${ }^{5}$ However, corticosteroids in some patients raise intraocular pressure, impair wound healing, suppress the immune system, increase infection risk, and contribute
Correspondence: Paul C Cockrum Health Kinetics, I02I Sterling Lane, Fort Worth, TX, USA

Email paulcockrum@gmail.com 
to cataracts. ${ }^{6,7}$ Clinically, NSAIDs are used by ophthalmologists in combination with or instead of corticosteroids. For ophthalmic surgical procedures, NSAIDs are useful for mydriasis, analgesia, and anti-inflammatory effects specific to ocular tissue. The FDA has approved these products in five indications: seasonal allergic conjunctivitis, pain associated with cataract surgery, inflammation associated with cataract surgery, pain associated with corneal refractive surgery, and inhibition of intraoperative miosis. While not approved by the FDA specifically for this use, NSAIDs are considered the standard of care by many anterior segment surgeons for preventing CME associated with cataract surgery. Recently, the American Academy of Ophthalmology stated in an ophthalmic technology assessment that there was good collective clinical evidence and rationale that anti-inflammatory use beginning 72 hours prior to surgery "reduces CME and improves vision in the short term". 8

Bromfenac in DuraSite (Sun Pharmaceuticals, Inc, Princeton, NJ, USA; BromSite ${ }^{\circledR}$; bromfenac ophthalmic solution $0.075 \%$ ) is indicated for the treatment of postoperative inflammation and prevention of ocular pain in patients undergoing cataract surgery. ${ }^{9}$ The formulation consists of DuraSite ${ }^{\circledR}$, a mucoadhesive matrix that swells in aqueous media and stabilizes molecules, contributing to longer ocular surface dwelling times. ${ }^{10}$ More specifically, DuraSite is a synthetic polymer of cross-linked polyacrylic acid that stabilizes small molecules in an aqueous matrix. Both nonclinical and clinical studies have shown the DuraSite drugdelivery system to be safe and nontoxic. ${ }^{11}$ The increased time that DuraSite remains on the eye allows lower concentrations of a given drug to be administered over a longer period. This offers convenience of dosing, reduces the potential of adverse side effects, and may lead to improved patient compliance.

In a recent rabbit study comparing three branded NSAIDs using FDA-approved human dosing, bromfenac in DuraSite demonstrated significantly greater NSAID concentrations compared to Prolensa ${ }^{\circledR}$ (bromfenac ophthalmic solution $0.07 \%$ ) and Ilevro ${ }^{\circledR}$ (nepafenac ophthalmic solution $0.3 \%$ ). The authors postulated that the DuraSite component of bromfenac in DuraSite enhanced ocular penetration throughout both anterior and posterior tissues. ${ }^{12}$ The human ocular pharmacokinetic (PK) details of bromfenac in DuraSite have not been published to date. Additionally, there have been no studies to address PK comparisons to Bromday ${ }^{\circledR}$ (bromfenac ophthalmic solution $0.09 \%$ ). To our knowledge, this study is the first to address both questions.

\section{Methods}

This was a multicenter, randomized, double-masked study approved by the New England Institutional Review Board.
All study materials were reviewed and approved prior to its commencement. The study was conducted in accordance with the Declaration of Helsinki, with all its applicable legal and regulatory requirements. Written informed consent was obtained from all subjects prior to study enrollment. After verifying that the subjects met all of the inclusion and exclusion criteria (ie, pregnant, nursing, or planning a pregnancy; female with a positive urine pregnancy test; had used [within 30 days of prior to beginning study treatment] or anticipated concurrent use of an investigational drug or device; had a condition or a situation that in the investigators' opinion may have put the subject at increased risk, confound study data, or interfered significantly with the subject's study participation), they were included into the study.

Randomization was stratified by site, and at each site subjects were then randomly assigned (1:1) to receive either bromfenac in DuraSite or bromfenac ophthalmic solution. Subjects were instructed to store the masked, multidose, opaque, white-cap test-article bottle at room temperature, and to administer one drop of test article onto their study eye once daily for 3 days. Dosing began 2 days prior to cataract surgery and continued on the day of surgery, 3 hours ( \pm 30 minutes) prior to surgery. Subjects were given a dosing diary to record application times and questioned to determine if they had followed the dosing schedule. Use of any drug containing bromfenac was prohibited for 2 weeks prior to surgery.

Three visits were required for full study participation, including the dosing phase and the evaluation phase: visit 1 (screening visit, day -14 to day 0 ), telephone contact (day 3 , dosing reminder), visit 2 (surgery, day 3 ), and visit 3 (postsurgical evaluation day 4). After the postsurgical safety evaluation, subjects were exited from the study. Adverse events were collected at the baseline exam, day of surgery, and postoperative Day 4. No other eyedrops were administered after the test article for at least 1 hour. Other ocular medications were allowed if administered at least 5 minutes prior to the investigational product.

Just prior to cataract surgery, after the patient was prepped and draped in a sterile manner, paracentesis performed, a cannula introduced into the anterior chamber, and at least $100 \mu \mathrm{L}$ aqueous humor aspirated. The sample was then immediately frozen and stored in a $-20^{\circ} \mathrm{C}$ freezer. The samples were then sent under dry ice to an independent bioanalytical laboratory. Bromfenac concentrations were assayed using high-performance liquid chromatography mass spectroscopy. Mean, maximum, minimum, and median aqueous humor concentrations of bromfenac for each treatment arm were summarized. Mean aqueous humor concentrations of bromfenac for the two treatment arms were compared statistically. 


\section{Results}

Demographic characteristics were similar between treatment groups. The mean age of all randomized subjects was 69.4 \pm 9.8 years: $70.6 \pm 10.1$ years in the bromfenac in DuraSite group and 68.2 \pm 9.4 years in the bromfenac ophthalmic solution group. Overall, 29 subjects $(48.3 \%, 29$ of 60$)$ were male: $18(60 \%, 18$ of 30$)$ in the bromfenac in DuraSite group, and $11(36.7 \%, 11$ of 30$)$ in the bromfenac ophthalmic solution group. The majority of the subjects, $91.7 \%$ (55 of 60 ), were Caucasian, and this proportion was similar between treatment groups. Overall, four subjects $(6.7 \%$, four of 30$)$ were African-American: one (3.3\%, one of 30) in the bromfenac in DuraSite group, and three (10\%, three of 30) in the bromfenac ophthalmic solution group. There was one Asian in the bromfenac in the DuraSite group.

As shown in Table 1 and Figure 1, the mean $( \pm \mathrm{SD})$ ocular aqueous humor concentration of bromfenac in the bromfenac in the DuraSite group was more than double $(49.33 \pm 41.87 \mathrm{ng} / \mathrm{mL})$ that of the bromfenac ophthalmic solution group $(23.65 \pm 16.31 \mathrm{ng} / \mathrm{mL})$. This difference was significant $(P=0.004, t$-test), indicating bromfenac in DuraSite administration resulted in higher bromfenac concentration in aqueous humor than bromfenac ophthalmic solution administration.

Comparison of means between the bromfenac in DuraSite and bromfenac ophthalmic solution groups was performed using a two-sample $t$-test. Examination of the univariate summary statistics indicated neither bromfenac in DuraSite nor bromfenac ophthalmic solution concentration levels followed a normal distribution. Therefore, the standard small-sample justification for the validity of the $t$-test did not apply to these data. Use of the $t$-test was justified by the study group randomization and large sample inferential statistical assumptions. To check the adequacy of the large sample approximation, 10,000 random permutations were generated, and the probability of observing a $t$-statistic $>3.08$ under the permutation distribution was estimated to be 0.0031 (with a standard error of 0.00056 ). This approximated $P$-value from the permutation distribution supports the observed

Table I Human aqueous humor bromfenac concentrations

\begin{tabular}{lll}
\hline $\begin{array}{l}\text { Descriptive } \\
\text { statistic }\end{array}$ & $\begin{array}{l}\text { Bromfenac } \\
\text { in DuraSite }\end{array}$ & $\begin{array}{l}\text { Bromfenac } \\
\text { ophthalmic solution }\end{array}$ \\
\hline $\begin{array}{l}\text { Evaluable samples, } \\
\mathrm{n}(\text { total } 58)\end{array}$ & 29 & 29 \\
Mean $(\mathrm{ng} / \mathrm{mL})$ & 49.33 & 23.65 \\
$\mathrm{SD}$ & 41.87 & 16.31 \\
Median $(\mathrm{ng} / \mathrm{mL})$ & 34.8 & 20.6 \\
Minimum $(\mathrm{ng} / \mathrm{mL})$ & 3.4 & 0.3 \\
Maximum $(\mathrm{ng} / \mathrm{mL})$ & 161 & 83 \\
\hline
\end{tabular}

$P$-value of 0.004 computed by the large sample-based $t$-test. No adverse events were reported in this study.

\section{Discussion}

NSAIDs are believed to exert therapeutic effects based on in vivo concentrations, and if those concentrations exceed the $\mathrm{IC}_{50}$ for $\mathrm{COX} 1$ and $\mathrm{COX} 2$ enzymes, and for what period of time. NSAIDs are considered time-dependent inhibitors of COX1 and COX2. Therefore, intraocular NSAID concentrations are expected to correlate with the efficacy of a given topical ocular therapy.

COX1 and COX2 enzymatic activity and the inhibition of both enzymes are foundational in understanding the pharmacologic actions of each NSAID. ${ }^{18} \mathrm{COX} 1$ is an omnipresent protein important to homeostasis, such as maintenance of renal function, platelet aggregation, and gastric protection. Comparatively, COX2 is an enzyme that is induced and largely responsible for prostaglandin creation during trauma within various tissue types, ${ }^{13}$ and has been well researched in models of ocular trauma as an enzyme responsible for increased prostaglandin activity. ${ }^{14-17}$

A single-dose study by Walters et al reported both PK results (maximum concentration $\left[\mathrm{C}_{\max }\right]$, time to $\mathrm{C}_{\max }$, and area under the curve $[\mathrm{AUC}]$ ), and in separate experimentation evaluating pharmacodynamic (PD) properties, COX1 and COX2 activity for amfenac, ketorolac, and bromfenac. ${ }^{18}$ This paper was published in 2007 and evaluated the relevant branded comparators (ie, Xibrom ${ }^{\circledR}$, Acular LS ${ }^{\circledR}$, and Nevanac ${ }^{\circledR}$ ). Results of PD studies are independent of the product and entirely dependent on methodology. For COX1inhibitory activity in sheep, the authors reported ketorolac to be the most potent. In the case of human recombinant COX2 assay, the most potent was reported to be amfenac. In these same models, the authors stated COX2 and COX1 inhibition was intermediary for bromfenac.

A more recent PK/PD study was published by Kida et al. ${ }^{19}$ This study evaluated diclofenac, amfenac, and bromfenac. The authors reported the rank order of potency at human platelet COX1 and human recombinant COX 2 to be the same for each cyclooxygenase isoform: diclofenac $<$ amfenac $<$ bromfenac (ranked least to most potent). Interpretation of results across studies is quite challenging, due to differing instrumentation and methodologies. ${ }^{18}$ Therefore, small changes in experimental conditions may lead to very different interpretations. As reported by Walters et al:

... because many NSAIDs are time-dependent inhibitors, increasing assay incubation times will result in lower (more potent) $\mathrm{IC}_{50}$ values. Likewise, variations in other assay 


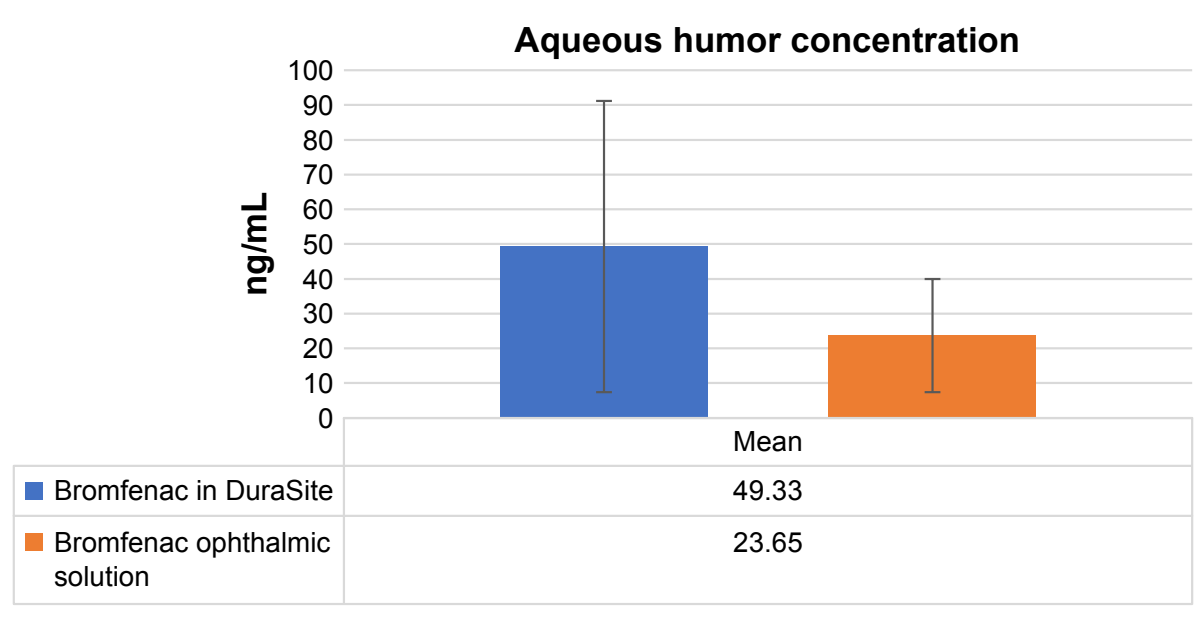

Figure I Aqueous humor bromfenac concentration comparison.

conditions (eg, temperature, source of enzymes, measuring oxygen consumption versus PG production) will affect the results.

Walters et al and Kida et al both measured isoforms at the same temperature $\left(37^{\circ} \mathrm{C}\right)$, but different times of incubation (COX1/COX2): 2/2 minutes vs $15 / 5$, respectively.

Kida et al used commercially available products for the in vivo/PK portion of their study. ${ }^{19}$ It should be noted nepafenac was the $0.1 \%$ solution, while bromfenac was the $0.09 \%$ ophthalmic solution. The $\mathrm{C}_{\max }$ of bromfenac, amfenac, and diclofenac in the retinochoroidal tissue were $15.8 \mathrm{ng} / \mathrm{g}$ at 30 minutes, $12.5 \mathrm{ng} / \mathrm{g}$ at 30 minutes, and $38.2 \mathrm{ng} / \mathrm{g}$ at 1 hour, respectively. Modeled PK parameters in aqueous humor and retinochoroidal tissues demonstrated the levels of the three NSAIDs were constantly higher than the $\mathrm{IC}_{50}$ of COX2 in aqueous humor. However, only bromfenac was constantly greater than the $\mathrm{IC}_{50}$ at its trough level in the retinochoroidal tissues.

No studies were found comparing NSAID single-dose AUC to multiple-dose AUC. However, Si et al ${ }^{10}$ examined aqueous concentrations for both single- and multiple-dose regimens, and found a 1.8-fold higher concentration at 2 hours for the multiple-dose (ie, three times daily for 14 days) DuraSite $0.09 \%$ formulation compared to the singledose DuraSite $0.09 \%$ formulation. The authors also reported 1.4-fold higher accumulation with the multiple dose vs the single dose. As such, this suggests comparable accumulation of bromfenac with multiple-dose regimens to single-dose regimens, regardless of the formulation. Furthermore, this difference is more pronounced with the DuraSite vehicle.

The concentration of bromfenac in the aqueous humor of 3-day once-daily dosing was higher in patients that were using bromfenac in DuraSite $(49.33 \pm 41.87 \mathrm{ng} / \mathrm{mL})$ compared to patients on the bromfenac ophthalmic solution $(23.65 \pm 16.31 \mathrm{ng} / \mathrm{mL})$. DuraSite appears to allow higher absorption and concentrations of bromfenac into the anterior chamber. This study provides key scientific insight for cataract surgeons. While bromfenac concentration differences within the formulations was similar $(0.075 \%$ and $0.09 \%$ ), the primary determinant of human aqueous bromfenac concentration appears to be that of DuraSite in bromfenac in DuraSite. As mentioned, DuraSite allows longer ocular surface-dwelling time for the bromfenac to absorb and exert its NSAID therapeutic effects. These data support that hypothesis without an increase in blurring or other adverse events.

While the current study reports anterior segment concentrations, similar proportional differences have been reported throughout the ocular tissue in preclinical studies. Si et al described the tissue concentration of DuraSite containing bromfenac was significantly higher than that of $0.09 \%$ bromfenac ophthalmic solution (Xibrom) in all ocular matrices, excluding the retina. The bromfenac concentration in the choroidal tissue achieved by the DuraSite formulation, in particular, was approximately triple that of concentrations obtained with the non-DuraSite formulation Xibrom. ${ }^{10}$ In the current study, the DuraSite component of the formulation demonstrated a double the difference in aqueous NSAID concentration.

Based on previous preclinical studies reporting ocular distribution in both the anterior and posterior segments of DuraSite-containing and not containing bromfenac formulations, the higher aqueous humor PK concentrations reported in this study would likely provide proportionally higher posterior segment concentrations in human ocular tissue. Therefore, for both anterior and posterior segments, 
the DuraSite component is expected to increase bromfenac delivery throughout ocular tissue and (based on previous PD assessments) inhibit inflammation from COX1 and COX2 activity, translating to improved effectiveness and resulting in quicker resolution of inflammation and pain following cataract surgery, as well as prevention or reduction of the incidence of CME. ${ }^{20}$

\section{Conclusion}

Bromfenac delivered in DuraSite enhances the ocular bioavailability of bromfenac, contributing to significantly higher NSAID concentrations in the aqueous humor compared to bromfenac ophthalmic solution.

\section{Acknowledgments}

The authors would like to acknowledge the contributions of Intertek Pharmaceutical Services for the bioanalytical portion of this study. This work was supported by Sun Pharmaceutical Industries Ltd (InSite Vision Inc at the time of the study).

\section{Disclosure}

TRW has performed consulting work for Allergan, Ocular Therapeutics, Nicox, and Sun Pharmaceutical Industries. PCC has performed consulting work for Sun Pharmaceutical Industries. The authors report no other conflicts of interest in this work.

\section{References}

1. Ahuja M, Dhake AS, Sharma SK, Majumdar DK. Topical ocular delivery of NSAIDs. AAPS J. 2008;10:229-241.

2. Colin J. The role of NSAIDs in the management of postoperative ophthalmic inflammation. Drugs. 2007;67:1291-1308.

3. Schalnus R. Topical nonsteroidal anti-inflammatory therapy in ophthalmology. Ophthalmologica. 2003;217:89-98.

4. Abel R, Abel AD. Perioperative antibiotic, steroidal, and nonsteroidal anti-inflammatory agents in cataract intraocular lens surgery. Curr Opin Ophthalmol. 1996;7:39-42.

Clinical Ophthalmology

\section{Publish your work in this journal}

Clinical Ophthalmology is an international, peer-reviewed journal covering all subspecialties within ophthalmology. Key topics include: Optometry; Visual science; Pharmacology and drug therapy in eye diseases; Basic Sciences; Primary and Secondary eye care; Patient Safety and Quality of Care Improvements. This journal is indexed on
5. Polansky J, Weinreb R. Steroids as anti-inflammatory agent. In: Sears M, editor. Pharmacology of the Eye. Heidelberg: Springer; 1984: 460-583.

6. Raizman M. Corticosteroid therapy of eye diseases: fifty years later. Arch Ophthalmol. 1996;114:1000-1001.

7. Jones BM, Neville MW. Nepafenac: an ophthalmic nonsteroidal antiinflammatory drug for pain after cataract surgery. Ann Pharmacother. 2013;47:892-896.

8. Kim SJ, Schoenberger SD, Thorne JE, Ehlers JP, Yeh S, Bakri SJ. Topical nonsteroidal anti-inflammatory drugs and cataract surgery: a report by the American Academy of Ophthalmology. Ophthalmology. 2015;122:2159-2168.

9. BromSite [prescribing information]. 2016. Available from: https://www. bromsite.com/pdf/BromSitePI.pdf. Accessed April 30, 2018.

10. Si EC, Bowman LM, Hosseini K. Pharmacokinetic comparisons of bromfenac in DuraSite and Xibrom. J Ocul Pharmacol Ther. 2010;27: $61-66$.

11. Bowman LM, Si E, Pang J, Archibald R, Friedlaender M. Development of a topical polymeric mucoadhesive ocular delivery system for azithromycin. J Ocul Pharmacol Ther. 2009;25:133-139.

12. Sheppard JD, Cockrum PC, Justice A, Jasek MC. In vivo pharmacokinetics of bromfenac ophthalmic solution $0.075 \%$, bromfenac ophthalmic solution $0.07 \%$, and nepafenac/amfenac ophthalmic suspension $0.3 \%$ in rabbits. Ophthalmol Ther. In press 2018.

13. Dubois RN, Abramson SB, Crofford L, et al. Cyclooxygenase in biology and disease. FASEB J. 1998;12:1063-1073.

14. Oka T, Shearer TR, Azuma M. Involvement of cyclooxygenase-2 in rat models of conjunctivitis. Curr Eye Res. 2004;29:27-34.

15. Guex-Crosier Y. [Non-steroidal anti-inflammatory drugs and ocular inflammation]. Klin Monbl Augenheilkd. 2001;218:305-308. French.

16. Bonazzi A, Mastyugin V, Mieyal PA, etal. Regulation of cyclooxygenase-2 by hypoxia and peroxisome proliferators in the corneal epithelium. J Biol Chem. 2000;275:2837-2844.

17. Masferrer JL, Kulkarni PS. Cyclooxygenase-2 inhibitors: a new approach to the therapy of ocular inflammation. Surv Ophthalmol. 1997;41: S35-S40.

18. Walters T, Raizman M, Ernest E, Gayton J, Lehman J. In vivo pharmacokinetics and in vitro pharmacodynamics of nepafenac, amfenac, ketorolac, and bromfenac. J Cataract Refract Surg. 2007;33:1539-1545.

19. Kida T, Kozai S, Takahashi H, Isaka M, Tokushige H, Sakamoto T. Pharmacokinetics and efficacy of topically applied nonsteroidal antiinflammatory drugs in retinochoroidal tissues in rabbits. PLoS One. 2014;9:e96481.

20. Shafiee A, Bowman LM, Hou E, Hosseini K. Aqueous humor penetration of ketorolac formulated in DuraSite or DuraSite 2 delivery systems compared to Acular LS in rabbits. J Ocul Pharmacol Ther. 2013;29: $812-816$.

PubMed Central and CAS, and is the official journal of The Society of Clinical Ophthalmology (SCO). The manuscript management system is completely online and includes a very quick and fair peer-review system, which is all easy to use. Visit http://www.dovepress.com/ testimonials.php to read real quotes from published authors. 